\title{
IMPLANTAÇÃO DE SISTEMA DE GESTÃO AMBIENTAL EM UMA INDÚSTRIA DE LATICÍNIOS
}

\author{
Wanderley Alves Rabelo ${ }^{1}$ \\ Cooperativa Agropecuária do Vale do Paracatu Ltda
}

Endereço $^{1}$ : Rua Melquíades Gonçalves Carvalho, 378 - Bairro Bela Vista - Paracatu-MG CEP: 38600-000 Tel: (38) 36726855 e-mail:wrambiente@yahoo.com.br

\section{Resumo}

O trabalho em questão foi desenvolvido com o objetivo de constatar os benefícios obtidos em uma Indústria de Laticínios após a implantação de um Sistema de Gestão Ambiental (SGA). A indústria situada na cidade de Paracatu-MG, recebe um volume aproximado de 200.000 litros de leite por dia, onde parte dele é processado para a produção de derivados e o restante é comercializado a granel. Devido a grande diversificação de produtos lácteos elaborados pela mesma, é possível quantificar todos os aspectos ambientais e os impactos gerados no empreendimento. Durante os processos de produção tem-se a geração de efluentes líquidos, resíduos sólidos, e, bem como a utilização de recursos naturais como água, madeira e energia elétrica. Com a implantação do SGA foi possível detectar as melhorias do desempenho ambiental obtidas após a implantação do programa de gestão, para isso foram implantados sistema de monitoramento total do processo, como uso da água, geração de efluente líquido, geração de resíduos sólidos, etc. Durante a implantação do SGA foi-se adotadas medidas para que toda a disposição final de resíduos sólidos e líquidos fosse realizada de maneira ambientalmente correta. Os resultados mostraram que o SGA trouxe vários benefícios para a empresa, que passou a tratar de maneira mais consciente o uso dos recursos naturais.

\footnotetext{
Abstract

The work in question was developed in order to realize the benefits in a Dairy Industry after the implementation of an Environmental Management System (EMS). The industry in the city of Paracatu, Minas Gerais, receives an approximate volume of 200,000 liters of milk per day, where part of it is processed for the production of oil products and the rest is sold in bulk. Due to the great diversification of dairy products made by the same, it is possible to quantify the environmental aspects and impacts generated in the project. During the production processes is the generation of wastewater, solid wastes, and, as well as the use of natural resources such as water, wood and electricity. With the EMS was possible to detect improvements in environmental performance achieved after the implementation of the management program for this were deployed in total process monitoring system, such as water use, generation of liquid waste, solid waste generation,
} 
etc. During the EMS was to measures adopted for the entire final disposal of solid and liquid wastes were carried out in an environmentally friendly way. The results showed that the EMS has brought many benefits to the company, which has treated more consciously use of natural resources.

Palavras-Chave: Sistema de Gestão Ambiental, efluente líquido, recursos naturais.

\section{1 - INTRODUÇÃO}

O ambiente da globalização econômica está impondo limites e determinações à sobrevivência de empresas, grandes ou pequenas, face à questão ambiental e à consequente necessidade de conhecer e reavaliar, sob a nova ótica, as diferentes atividades econômicas e, mais que isso, todo o ciclo de vida dos produtos das empresas. Todo este processo faz com que as empresas tenham um grande desafio, tornar-se ambientalmente correto, ao menor custo, mantendo a competitividade, esta é a equação desejável. Mas para atingir esse patamar é necessário que as empresas busquem uma avaliação completa de seu atual estágio bem como estabeleça metas ambientais a serem alcançadas dentro do seu processo industrial e principalmente organizacional (REVISTA GESTÃO AMBIENTAL - COMPROMISSO DA EMPRESA, 1996).

O SGA promove continuamente as políticas corporativas, programas e desempenho ambiental, levando em consideração o desenvolvimento tecnológico, o conhecimento científico, as necessidades do consumidor e as expectativas da comunidade, partindo dos requisitos da legislação ambiental, tendo como referência a ISO 14.000. A gestão ambiental é a forma pela qual a empresa se mobiliza, interna e externamente, na conquista da qualidade ambiental desejada, buscando atingir as suas metas, ao menor custo, de forma permanente. A tendência atual é que as empresas façam do seu desempenho ambiental um fator diferencial no mercado, mostrando o compromisso da mesma com o meio ambiente, o que significa adotar requisitos internos que possa levar a empresa a estar sempre em processo de melhoria contínua (REVISTA INDÚSTRIA DE LATICÍNIOS, 2007).

De acordo com a norma ISO 14001, o sistema de gestão ambiental prevê a adoção de ações preventivas a ocorrência de impactos adversos ao meio ambiente, assumindo uma postura pró-ativa com relação às questões ambientais, com o objetivo de assegurar a melhoria contínua do desempenho ambiental da empresa. Trata-se de um processo em equilíbrio dinâmico retroalimentado, fazendo com que os ciclos do SGA se desenvolvam em um plano superior de qualidade (REVISTA GESTÃO AMBIENTAL - COMPROMISSO DA EMPRESA, 1996).

As indústrias pequenas e médias representam mais de $90 \%$ das empresas brasileiras, estas enfrentam diversos problemas que afetam diretamente a sua sobrevivência, o que dificulta os investimentos principalmente nas questões ambientais. Porém o crescente interesse pela 
preservação do meio ambiente leva progressivamente a conscientização da população em consumir produtos e serviços que gerem menor impacto ambiental, o que exige por parte das empresas uma adequação de seus processos produtivos (SILVA, et al., 2000).

Dentro deste contexto industrial está inserida a Indústria de Laticínios, que tem como principal matéria-prima o leite, que através de seu processamento tem-se a obtenção de vários produtos derivados como queijos, manteiga, leite pasteurizado, ricota, doce de leite, iogurte, requeijão, bebida láctea pasteurizada e outros.

No processo industrial ocorre a geração de efluentes líquidos originados de diversas atividades industriais, que contém resíduos de leite e dos seus derivados, resíduos de detergentes, resíduos de produtos químicos diversos diluídos nas águas de lavagem dos equipamentos, pisos, tubulações e esgotos sanitários quando estes não são destinados para rede pública. Ainda são gerados resíduos sólidos provenientes do setor administrativo e da linha de processo, como: papel, papelão, plástico, restos de produção, cinzas e outros.

Com base nos argumentos acima descritos e reconhecendo a importância da preservação ambiental pelas indústrias diante do contexto da sustentabilidade, o presente trabalho visa demonstrar na prática a aplicabilidade do SGA, bem como apresentar os resultados obtidos no desempenho ambiental após a implantação do mesmo na Indústria de Laticínios de médio porte situada na cidade de Paracatu-MG.

O gerenciamento ambiental de um laticínio é de grande importância para minimizar os impactos ambientais gerados por esta atividade industrial, reduzindo custos, aumentando o lucro, atendendo as legislações ambientais vigentes e melhorando o desempenho ambiental da empresa através de melhorias contínuas.

O presente trabalho é de grande importância, pois este vai apresentar os resultados obtidos com a implantação de um sistema de gestão ambiental em um laticínio, mostrando de maneira simples e objetiva os resultados obtidos após a implantação do SGA.

\section{2 - OBJETIVO}

O objetivo geral deste trabalho é apresentar os resultados obtidos após a implantação do sistema de gestão ambiental na indústria de laticínios, com ganhos na economia de água e outros aspectos importantes para a indústria de laticínios.

\section{3 - MATERIAIS E MÉTODOS}

A indústria de laticínios em estudo forma juntamente com outras unidades a Cooperativa Agropecuária do Vale do Paracatu Ltda, está situada no Bairro Alvorada na cidade de Paracatu MG, com uma área de $10.000 \mathrm{~m}^{2}$, sendo destes $2.500 \mathrm{~m}^{2}$ de construção. Atualmente a indústria 
recebe cerca de 240.000 litros de leite por dia, onde cerca de $45 \%$ deste volume é destinado para a produção de derivados, sendo: Queijos (Prato, mussarela, minas padrão e minas frescal), ricota, doce de leite, requeijão barra e cremoso, leite pasteurizado, bebida láctea pasteurizada, iogurte e manteiga. O restante do volume, cerca de $55 \%$ é padronizado e resfriado, sendo vendido a granel para empresas terceiras.

Foi implantado na indústria um modelo de SGA baseado nos requisitos danorma NBR ISO 14.000, este modelo foi aplicado na empresa em todos os setores, onde foi dividido nas seguintes etapas:

$1^{\text {a }}$ Etapa: Realização de Diagnóstico geral da empresa com levantamento da situação atual da empresa e identificação dos aspectos e impactos ambientais;

$2^{a}$ Etapa: Implantação do plano de ação com procedimentos de controle, ações corretivas, indicadores de desempenho, estabelecimento de metas, gerenciamento dos resíduos sólidos e liquidos;

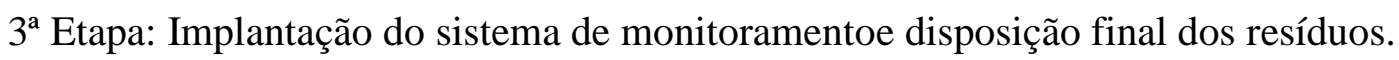

Para avaliar os resultados obtidos com a implantação do Programa de Sistema de Gestão Ambiental foi realizado o monitoramento no período de Setembro/10 a Setembro/11 de alguns parâmetros que permitisse avaliar e medir o empenho ambiental da empresa durante este período. Sendo assim foi possível observar as melhorias obtidas com a implementação do SGA na indústria de laticínios, avaliando o desempenho ambiental obtido após a implementação do SGA. Alguns parâmetros monitorados dependeram de análises laboratoriais, como DBO, DQO, SST, pH e OG. Os outros indicadores como consumo de água, geração e destinação de resíduos sólidos, geração de efluente líquido e outros foram monitorados nas planilhas criadas e implementadas dentro do programa.

É importante destacar que a empresa já desenvolvia anteriormente algumas ações no sentido de minimizar e controlar alguns impactos ambientais, com o monitoramento de alguns indicadores ambientais. A discussão deste trabalho é com o objetivo de identificar as melhorias obtidas com a implantação do modelo proposto do Programa de Sistema de Gestão Ambiental, bem como avaliar outros indicadores.

\section{1 - IDENTIFICAÇÃO E QUANTIFICAÇÃO DOS INDICADORES DE DESEMPENHO AMBIENTAL}

A identificação dos indicadores de desempenho ambiental é de grande importância visando o comparativo antes e depois da implantação do SGA, haja vista que todos os indicadores serão monitorados diariamente. 


\subsection{1 - Água}

A empresa consome água proveniente de captação subterrânea de doispoços artesianos, os quais possuem outorga. A média de consumo antes da implantação do SGA com uma recepção de leite de 170.000 litros por dia está relacionada no quadro1.

Quadro1: Consumo de Água

\begin{tabular}{|l|c|}
\hline Litros de água/dia & $225 \mathrm{~m}^{3}$ \\
\hline Litros de água/mês & $6.750 \mathrm{~m}^{3}$ \\
\hline Coeficiente de consumo: Litros água/litros de leite & 1,21 \\
\hline
\end{tabular}

Fonte: Autor

\subsection{2 - Efluente Líquido}

A empresa gerava emmédia $180 \mathrm{~m}^{3}$ litros/diade efluente líquido, proveniente do processamento do leite e industrialização dos produtos: queijos, manteiga, leite pasteurizado, requeijão, iogurte e doce de leite. A diferença entre a água consumida e o efluente líquido gerado são as águas residuárias reaproveitadas pela empresa as quais estão mais limpas e são utilizadas para irrigação de pastagens da empresa.

\subsection{3 - Resíduos Sólidos}

No quadro 2, tem-se a quantificação dos resíduos sólidos geradosem toda a empresa, sendo: escritório, áreas externas e área industrial. Esta quantificação foi realizada após a implantação do monitoramento dos resíduos sólidos, procedimento que foi executado no mês de Fevereiro/11.

Quadro 2: Quantidades de resíduos sólidos gerados na indústria

\begin{tabular}{|c|c|}
\hline Papel/papelão & $650,0 \mathrm{~kg} / \mathrm{mês}$ \\
\hline Plástico & $880,0 \mathrm{~kg} / \mathrm{mês}$ \\
\hline Metal & $350,0 \mathrm{~kg} / \mathrm{mês}$ \\
\hline Carvão & $2.500,0 \mathrm{~kg} / \mathrm{mês}$ \\
\hline Cinzas & $150,0 \mathrm{~kg} / \mathrm{mês}$ \\
\hline Lodo (Sólidos Gordurosos) & $500,0 \mathrm{~kg} / \mathrm{mês}$ \\
\hline Óleo lubrificante usado & 30 litros $/ \mathrm{mês}$ \\
\hline Resíduos contaminados c/ óleo & $01 \mathrm{galão} / \mathrm{mês}$ \\
\hline Lâmpadas fluorescentes & 05 unidades $/ \mathrm{mês}$ \\
\hline Resíduos orgânicos & $100 \mathrm{~kg} / \mathrm{mês}$ \\
\hline
\end{tabular}

Fonte: Autor

\subsection{4 - Consumo de energia}

A energia consumida pela indústria no mês de Fevereiro/11 foi considerado bastante alto, tendo em vista o alto custo da mesma, conforme o quadro 3: 
Quadro 3: Consumo de Energia

\begin{tabular}{|c|}
\hline Média de $111.000 \mathrm{KW} / \mathrm{mês}$ \\
\hline Média de $0,600 \mathrm{KW} /$ litro de leite \\
Fonte: Autor
\end{tabular}

\subsection{5 - Consumo de energia vegetal (madeira)}

Durante o processo produtivo, a empresa consome energia vegetal (madeira) para geração de vapor, sendo que o consumo abaixo está baseado em uma recepção média de leite de 180.000 litros, sabendo-se que em torno de $40 \%$ deste leite é industrializado em produtos derivados, portanto no mês de outubro/10 o consumo era de $240 \mathrm{~m}^{3}$ delenha por mês. Toda madeira utilizada na indústria de laticínios é oriunda de floresta plantada, sendo a espécie eucalipto a utilizada pela empresa. Toda madeira adquirida é licenciada pelos órgãos ambientais e seu consumo é autorizado pelo IEF Instituto Estadual de Florestas de Minas Gerais.

A madeira é utilizada em três caldeiras, sendo que duas destas são utilizadas apenas nos finais de semanas e de segunda-feira a sexta-feira utiliza-se a caldeira com maior capacidade de produção. A queima da lenha gera os resíduos de carvão e cinzas, os quais são utilizados na adubação de pastagem.

\section{2 - IMPLEMENTAÇÃO DO PROGRAMA DE SISTEMA DE GESTÃO AMBIENTAL NA INDÚSTRIA DE LATICÍNIOS}

Após a etapa de levantamento de dados, identificação dos aspectos e impactos ambientais, iniciou de fato a implementação do SGA, com a adoção de ações desenvolvidas visando melhorar o desempenho ambiental da indústria. No quadro 4 foi relacionado às ações desenvolvidas adotadas de acordo com os impactos ambientais gerados em cada setor, visando melhorar os indicadores ambientais e o desempenho ambiental.

Quadro 4: Implementação do Programa SGA

\begin{tabular}{|c|c|c|c|c|}
\hline $\begin{array}{c}\text { Linha de } \\
\text { produção/Setor }\end{array}$ & Aspectos Ambientais & $\begin{array}{c}\text { Impactos } \\
\text { Ambientais }\end{array}$ & Ações Propostas e Implementadas & $\begin{array}{c}\text { Indicador de Desempenho Ambiental } \\
\text { e/ou Controle }\end{array}$ \\
\hline \multirow[b]{2}{*}{$\begin{array}{l}\text { Setor produção } \\
\text { de vapor } \\
\text { (caldeiras) }\end{array}$} & $\begin{array}{l}\text { - Geração de resíduos } \\
\text { sólidos na forma de cinzas, } \\
\text { carvão e cavacos. }\end{array}$ & $\begin{array}{l}\text { Poluição do } \\
\text { solo }\end{array}$ & \multirow{2}{*}{$\begin{array}{l}\text { - Os resíduos como carvão e cinzas } \\
\text { são recolhidos diariamente e } \\
\text { distribuídos na pastagem, sendo } \\
\text { utilizados como adubo orgânico. Os } \\
\text { cavacos oriundos da limpeza do } \\
\text { local de estocagem de madeira são } \\
\text { reaproveitados na caldeira ou } \\
\text { destinados para compostagem } \\
\text { orgânica. }\end{array}$} & - Consumo de Madeira \\
\hline & $\begin{array}{l}\text { - Geração de emissões } \\
\text { atmosféricas. }\end{array}$ & $\begin{array}{l}\text { Poluição } \\
\text { atmosférica }\end{array}$ & & - Medição de MP das chaminés \\
\hline
\end{tabular}




\begin{tabular}{|c|c|c|c|c|}
\hline & & & $\begin{array}{l}\text { - Utilização de filtros nas chaminés } \\
\text { das caldeiras. } \\
\text { - Queima de madeira seca visando } \\
\text { reduzir a emissão de Material } \\
\text { Particulado das caldeiras. }\end{array}$ & \\
\hline & $\begin{array}{l}\text { - Geração de efluente } \\
\text { líquido na limpeza de } \\
\text { balões de soro e } \\
\text { condensação das caldeiras. }\end{array}$ & Poluição hídrica & $\begin{array}{l}\text { - Os resíduos de soro e resíduos } \\
\text { químicos, provenientes do enxágüe } \\
\text { e limpeza dos balões de estocagem } \\
\text { do soro distribuídos para os } \\
\text { produtores, são encaminhados para } \\
\text { o sistema de tratamento primário e } \\
\text { posteriormente para a ETE da } \\
\text { COPASA. } \\
\text { - Os condensados das caldeiras são } \\
\text { reaproveitados para irrigação de } \\
\text { pastagens. }\end{array}$ & - Consumo de água \\
\hline \multirow{4}{*}{$\begin{array}{l}\text { Setor de } \\
\text { manutenção }\end{array}$} & $\begin{array}{l}\text { - Geração de resíduos } \\
\text { sólidos na forma sucatas de } \\
\text { metais. }\end{array}$ & $\begin{array}{l}\text { Poluição do } \\
\text { solo }\end{array}$ & $\begin{array}{l}\text { - Estes resíduos são encaminhados } \\
\text { para a área de reciclagem, os quais } \\
\text { são recolhidos por empresa de } \\
\text { reciclagem de resíduos sólidos. }\end{array}$ & $\begin{array}{l}\text { - Planilha de controle de destinação de } \\
\text { sucatas de metais para reciclagem }\end{array}$ \\
\hline & $\begin{array}{l}\text { - Geração de resíduos } \\
\text { perigosos contaminados } \\
\text { com óleo lubrificante. }\end{array}$ & $\begin{array}{l}\text { Poluição do } \\
\text { solo }\end{array}$ & $\begin{array}{l}\text { - Estes resíduos são destinados para } \\
\text { empresa autorizada pela FEAM a } \\
\text { qual possui aterro especial para } \\
\text { resíduos perigosos. }\end{array}$ & $\begin{array}{c}\text { - Planilhade Controle de Destinação de } \\
\text { resíduos contaminados com óleo } \\
\text { lubrificante }\end{array}$ \\
\hline & $\begin{array}{l}\text { - Troca de Óleo } \\
\text { Lubrificante de } \\
\text { Equipamentos com geração } \\
\text { de resíduo perigoso. }\end{array}$ & $\begin{array}{l}\text { Poluição do } \\
\text { solo e poluição } \\
\text { hidríca }\end{array}$ & $\begin{array}{l}\text { - O resíduo perigoso óleo } \\
\text { lubrificante usado é encaminhado } \\
\text { para empresa de re-refino } \\
\text { responsável pela reciclagem do óleo } \\
\text { lubrificante. A empresa possui } \\
\text { licença ambiental do IBAMA e } \\
\text { órgãos ambientais estaduais. }\end{array}$ & $\begin{array}{l}\text { - Planilha de controle de destinação de } \\
\text { óleo para Re-rrefino. }\end{array}$ \\
\hline & $\begin{array}{l}\text { - Substituição e troca de } \\
\text { lâmpadas fluorescentes } \\
\text { queimadas. }\end{array}$ & $\begin{array}{l}\text { Poluição } \\
\text { solo }\end{array}$ & $\begin{array}{l}\text { - As lâmpadas fluorescentes } \\
\text { queimadas, as quais são substituídas } \\
\text { nos setores da indústriasão } \\
\text { recolhidas, estocadas e, } \\
\text { posteriormente, encaminhadas para } \\
\text { empresa de reciclagem licenciada } \\
\text { pela FEAM. }\end{array}$ & $\begin{array}{c}\text { - Planilha de controle de destinação de } \\
\text { lâmpadas para reciclagem. }\end{array}$ \\
\hline $\begin{array}{l}\text { Setor de } \\
\text { almoxarifado }\end{array}$ & $\begin{array}{l}\text { - Descarte de materiais } \\
\text { sólidos como papel, } \\
\text { papelão e plástico. }\end{array}$ & $\begin{array}{l}\text { Poluição } \\
\text { solo }\end{array}$ & $\begin{array}{l}\text { - Os resíduos sólidos são } \\
\text { encaminhados para o local de } \\
\text { estocagem e recolhidos diariamente } \\
\text { por empresa de reciclagem, } \\
\text { licenciada e autorizada pela FEAM. }\end{array}$ & $\begin{array}{l}\text { - Planilha de controle de destinação de } \\
\text { resíduos sólidos para reciclagem. }\end{array}$ \\
\hline \multirow[t]{2}{*}{$\begin{array}{l}\text { Escritório/guarit } \\
\text { a, galpão longa } \\
\text { vida }\end{array}$} & $\begin{array}{l}\text { - Descarte de materiais } \\
\text { sólidos como papel e } \\
\text { plástico. }\end{array}$ & $\begin{array}{l}\text { Poluição } \\
\text { solo }\end{array}$ & $\begin{array}{l}\text { - Os resíduos sólidos são } \\
\text { encaminhados para o local de } \\
\text { recolhimento, quando são } \\
\text { recolhidos diariamente por empresa } \\
\text { de reciclagem licenciada e } \\
\text { autorizada pela FEAM. }\end{array}$ & $\begin{array}{l}\text { - Planilha de controle de destinação de } \\
\text { resíduos sólidos para reciclagem. }\end{array}$ \\
\hline & $\begin{array}{l}\text { - Geração de esgoto } \\
\text { sanitário. }\end{array}$ & $\begin{array}{l}\text { Poluição } \\
\text { Hidríca }\end{array}$ & $\begin{array}{l}\text { - O esgoto sanitário é encaminhado } \\
\text { para o tratamento na ETE da } \\
\text { COPASA, sendo que o mesmo é }\end{array}$ & - Conta pagamento da COPASA \\
\hline
\end{tabular}




\begin{tabular}{|c|c|c|c|c|}
\hline & & & $\begin{array}{l}\text { lançado na rede pública separado do } \\
\text { esgoto industrial. }\end{array}$ & \\
\hline $\begin{array}{l}\text { Vestiários } \quad \mathrm{e} \\
\text { refeitório }\end{array}$ & \begin{tabular}{lrr}
\multicolumn{1}{c}{ Geração } & de & esgoto \\
sanitário & e & resíduos \\
orgânicos. & & \\
&
\end{tabular} & $\begin{array}{l}\text { Poluição do } \\
\text { Solo } \\
\text { Poluição } \\
\text { Hidríca }\end{array}$ & $\begin{array}{l}\text { - O esgoto sanitário é encaminhado } \\
\text { para o tratamento na ETE } \\
\text { COPASA. } \\
\text { - Os resíduos orgânicos (restos de } \\
\text { comidas) são recolhidos e } \\
\text { destinados para o aterro municipal. }\end{array}$ & - Não foi adotado controle \\
\hline $\begin{array}{l}\text { Recepção de } \\
\text { leite }\end{array}$ & $\begin{array}{l}\text { - Geração de efluente } \\
\text { líquido na limpeza e } \\
\text { sanitização dos tanques a } \\
\text { granel e limpeza do piso. } \\
\text { - Descarte de materiais } \\
\text { sólidos na forma de papel. }\end{array}$ & $\begin{array}{l}\text { Poluição do } \\
\text { solo }\end{array}$ & $\begin{array}{l}\text { - O efluente líquido são destinados } \\
\text { através de tubulações para o } \\
\text { Sistema de Tratamento Primário e } \\
\text { encaminhados para a ETE visando } \\
\text { tratamento secundário e destinação } \\
\text { final. } \\
\text { - Os resíduos sólidos, como o papel, } \\
\text { são encaminhados para o local de } \\
\text { estocagem, quando são recolhidos } \\
\text { diariamente por empresa de } \\
\text { reciclagem licenciada pela FEAM. } \\
\text { - Assoluções químicas são } \\
\text { reaproveitadas dentro do próprio } \\
\text { sistema CIP, evitando o descarte. }\end{array}$ & $\begin{array}{l}\text { - Planilhas de monitoramento do efluente } \\
\text { líquido e Destinação de resíduos sólidos } \\
\text { - Consumo de Água } \\
\text { - Monitoramento dos Parâmetros de DBO, } \\
\text { DQO, SST, ÓLEOS e GRAXAS, etc. }\end{array}$ \\
\hline $\begin{array}{c}\text { Pasteurização } \\
\text { de Leite }\end{array}$ & $\begin{array}{l}\text { - Geração de efluente } \\
\text { líquido na limpeza e } \\
\text { sanitização dos tanques de } \\
\text { estocagem, linhas de } \\
\text { processo, equipamentos e } \\
\text { limpeza de piso e paredes. } \\
\text { - Descarte de materiais } \\
\text { sólidos na forma de papel. }\end{array}$ & $\begin{array}{l}\text { Poluição do } \\
\text { solo }\end{array}$ & $\begin{array}{l}\text { - Os resíduos de leite, provenientes } \\
\text { do primeiro enxágüe dos balões e } \\
\text { linhas de processo, são } \\
\text { reaproveitados e encaminhados para } \\
\text { os balões de soro, de onde são } \\
\text { distribuídos para os produtores de } \\
\text { leite para alimentação animal. } \\
\text { - Os produtos químicos utilizados } \\
\text { nos equipamentos e linhas de } \\
\text { processo são reaproveitados pelo } \\
\text { sistema CIP, evitando o descarte das } \\
\text { mesmas. } \\
\text { - Os resíduos de limpeza da } \\
\text { padronizadora são encaminhados } \\
\text { para a Estação de Tratamento de } \\
\text { Efluente da COPASA, após passar } \\
\text { pelo sistema de tratamento } \\
\text { primário. pasto de } \\
\text {-Durante o processo de } \\
\text { padronização, a água utilizada para } \\
\text { resfriar as padronizadoras é } \\
\text { reaproveitada para a irrigação das } \\
\text { pastagens através do sistema de } \\
\text { coleta. }\end{array}$ & $\begin{array}{l}\text { - Controle de destinação de resíduos } \\
\text { sólidos } \\
\text { - Planilhas de monitoramentos de efluente } \\
\text { líquido e Controle de Uso de Água. } \\
\text { - Monitoramento dos Parâmetros de DBO, } \\
\text { DQO, SST, ÓLEOS e GRAXAS, etc. } \\
\text { - Consumo de Água }\end{array}$ \\
\hline Envase de leite & 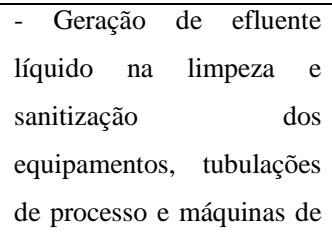 & $\begin{array}{l}\text { Poluição } \\
\text { Hídrica }\end{array}$ & $\begin{array}{l}\text { - Os resíduos de leite, provenientes } \\
\text { da limpeza interna das máquinas e } \\
\text { tubulações, são encaminhados para } \\
\text { o sistema de tratamento primário e } \\
\text { em seguida são destinados para a }\end{array}$ & $\begin{array}{l}\text { - Planilhas de monitoramentos de efluente } \\
\text { líquido e Controle de Uso de Água. }\end{array}$ \\
\hline
\end{tabular}




\begin{tabular}{|c|c|c|c|c|}
\hline & $\begin{array}{l}\text { envase. } \\
\text { - Descarte de resíduos } \\
\text { sólidos na forma de papel, } \\
\text { papelão e plástico. }\end{array}$ & $\begin{array}{l}\text { Poluição } \\
\text { solo }\end{array}$ & $\begin{array}{l}\text { ETE da COPASA. } \\
\text { - Toda limpeza realizada nos } \\
\text { equipamentos é feita via CIP, } \\
\text { circuito interno, o que possibilita } \\
\text { todo o reaproveitamento das } \\
\text { soluções químicas. } \\
\text { - Todos os resíduos líquidos gerados } \\
\text { no processo, provenientes da } \\
\text { limpeza de paredes e pisos, são } \\
\text { encaminhados para a ETE- } \\
\text { COPASA, para o devido tratamento. } \\
\text { - Os resíduos sólidos como: papel, } \\
\text { papelão e outros, são encaminhados } \\
\text { para local de estocagem e } \\
\text { recolhimento, os quais são } \\
\text { destinados para empresa de } \\
\text { reciclagem licenciada pela FEAM. }\end{array}$ & $\begin{array}{l}\text { - Monitoramento dos Parâmetros de DBO, } \\
\text { DQO, SST, ÓLEOS e GRAXAS, etc. } \\
\text { - Consumo de Água } \\
\text { - Controle de destinação de resíduos } \\
\text { sólidos }\end{array}$ \\
\hline $\begin{array}{l}\text { Fábrica de } \\
\text { requeijão e doce } \\
\text { de leite }\end{array}$ & $\begin{array}{l}\text { - Geração de efluente } \\
\text { líquido devido limpeza dos } \\
\text { equipamentos, utensílios e } \\
\text { outros após a produção de } \\
\text { requeijão e doce de leite. } \\
\text { - Descarte de resíduos } \\
\text { sólidos na forma de papel, } \\
\text { plástico e restos de massas } \\
\text { orgânicas. }\end{array}$ & $\begin{array}{l}\text { Poluição } \\
\text { solo }\end{array}$ & $\begin{array}{l}\text { - Os resíduos de massa são } \\
\text { recolhidos e encaminhados para o } \\
\text { recipiente de coleta de resíduos } \\
\text { orgânicos do setor. Estes resíduos } \\
\text { são encaminhados para o aterro } \\
\text { Municipal da cidade. } \\
\text { - Todo o soro, gerado no setor, é } \\
\text { recolhido e destinado para } \\
\text { distribuição para os produtores de } \\
\text { leite, visando alimentação animal. } \\
\text { - O efluente líquidoproveniente da } \\
\text { limpeza química dos equipamentos, } \\
\text { são encaminhados para a ETE- } \\
\text { COPASA para o devido tratamento. } \\
\text { - Os resíduos sólidos como: papel e } \\
\text { plástico, são encaminhados para o } \\
\text { local de coleta, de onde são } \\
\text { destinados para a reciclagem. }\end{array}$ & $\begin{array}{l}\text { - Planilhas de monitoramentos de efluente } \\
\text { líquido e Controle de Uso de Água. } \\
\text { - Monitoramento dos Parâmetros de DBO, } \\
\text { DQO, SST, ÓLEOS e GRAXAS, etc. } \\
\text { - Consumo de Água } \\
\text { - Controle de destinação de resíduos } \\
\text { sólidos }\end{array}$ \\
\hline $\begin{array}{l}\text { Fabrica } \\
\text { manteiga }\end{array}$ & $\begin{array}{l}\text { - Geração de efluente } \\
\text { líquido devido a } \\
\text { higienização de todos os } \\
\text { equipamentos do setor. } \\
\text { - Descarte de materiais } \\
\text { sólidos na forma de papel, } \\
\text { papelão e plástico. }\end{array}$ & $\begin{array}{l}\text { Poluição } \\
\text { solo }\end{array}$ & $\begin{array}{l}\text { - Os resíduos de manteiga são } \\
\text { reaproveitados, misturando-se junto } \\
\text { ao creme para padronização e } \\
\text { pasteurização. } \\
\text { - Os resíduos líquidos, gerados no } \\
\text { processo de limpeza, são } \\
\text { encaminhados para a estação de } \\
\text { tratamento de esgoto da COPASA, } \\
\text { depois de passar pelo processo de } \\
\text { tratamento primário. } \\
\text { - Os resíduos sólidos, são } \\
\text { encaminhados para o local de } \\
\text { estocagem, onde diariamente são } \\
\text { recolhidos para a reciclagem. }\end{array}$ & $\begin{array}{l}\text { - Planilhas de monitoramentos de efluente } \\
\text { líquido e Controle de Uso de Água. } \\
\text { - Monitoramento dos Parâmetros de DBO, } \\
\text { DQO, SST, ÓLEOS e GRAXAS, etc. } \\
\text { - Consumo de Água } \\
\text { - Controle de destinação de resíduos } \\
\text { sólidos }\end{array}$ \\
\hline $\begin{array}{l}\text { Fábrica } \\
\text { iogurte }\end{array}$ & $\begin{array}{l}\text {-Geração de efluente } \\
\text { líquido durante o processo } \\
\text { de higienização do tanque }\end{array}$ & Poluição Hídrica & $\begin{array}{l}\text { - Os resíduos de iogurte são } \\
\text { reaproveitados e encaminhados para } \\
\text { os balões de soro, destinados para }\end{array}$ & $\begin{array}{c}\text { - Planilhas de monitoramentos de efluente } \\
\text { líquido e Controle de Uso de Água. }\end{array}$ \\
\hline
\end{tabular}




\begin{tabular}{|c|c|c|c|c|}
\hline & $\begin{array}{l}\text { iogurteiro, após envase do } \\
\text { iogurte, higienização da } \\
\text { bomba, linhas de processos } \\
\text { e máquinas de envase; } \\
\text {-Descarte de resíduos } \\
\text { sólidos. }\end{array}$ & Poluição do solo & $\begin{array}{l}\text { distribuição aos produtores, sendo } \\
\text { utilizados para alimentação animal. } \\
\text { - Os resíduos líquidos, provenientes } \\
\text { da limpeza química, serão } \\
\text { encaminhados para tratamento na } \\
\text { ETE da COPASA após tratamento } \\
\text { primário. } \\
\text { - Os resíduos sólidos são destinados } \\
\text { para empresa de reciclagem, após } \\
\text { recolhidos. }\end{array}$ & $\begin{array}{c}\text { - Monitoramento dos Parâmetros de DBO, } \\
\text { DQO, SST, ÓLEOS e GRAXAS, etc. }\end{array}$ \\
\hline $\begin{array}{l}\text { Fábrica de } \\
\text { queijo/embalage } \\
\text { m e expedição }\end{array}$ & $\begin{array}{l}\text { - Geração de efluente } \\
\text { líquido durante a limpeza } \\
\text { de formas, mesas, } \\
\text { equipamentos e utensílios } \\
\text { gerais; } \\
\text { - Limpeza de pisos e } \\
\text { paredes. } \\
\text { - Descarte de resíduos } \\
\text { sólidos orgânicos na forma } \\
\text { de restos de massa de } \\
\text { queijo. } \\
\text { - Descarte de resíduos } \\
\text { sólidos na forma de papel, } \\
\text { papelão e plástico. }\end{array}$ & $\begin{array}{l}\text { - Poluição } \\
\text { Hídrica }\end{array}$ & $\begin{array}{l}\text { - Os resíduos químicos, resultantes } \\
\text { da limpeza de formas e } \\
\text { equipamentos, são encaminhados } \\
\text { para a estação de tratamento de } \\
\text { esgoto da COPASA após tratamento } \\
\text { primário. } \\
\text { - Os resíduos de massa são } \\
\text { recolhidos e encaminhados para o } \\
\text { aterro Municipal. Todos os ralos } \\
\text { possuem telas, evitando que os } \\
\text { resíduos sejam levados para o } \\
\text { sistema de tratamento primário. } \\
\text { - Todas as mesas possuem coletores } \\
\text { que recebem o soro, proveniente da } \\
\text { massa cortada, no momento da } \\
\text { enformagem dos queijos, ou da } \\
\text { massa de mussarela, a qual é filada } \\
\text { no dia posterior. } \\
\text { - Todo o soro é reaproveitado, } \\
\text { sendo utilizado na produção de } \\
\text { Bebida Láctea Pasteurizada, Bebida } \\
\text { Láctea UHT, distribuído para os } \\
\text { produtores e parte é vendida a } \\
\text { granel. } \\
\text { - Os resíduos sólidos de papel e } \\
\text { para a reciclagem. }\end{array}$ & $\begin{array}{l}\text { - Planilhas de monitoramentos de efluente } \\
\text { líquido e Controle de Uso de Água. } \\
\text { - Monitoramento dos Parâmetros de DBO, } \\
\text { DQO, SST, ÓLEOS e GRAXAS, etc. } \\
\text { - Consumo de Água } \\
\text { - Controle de destinação de resíduos } \\
\text { sólidos }\end{array}$ \\
\hline
\end{tabular}

\section{4 - IMPLEMENTAÇÃO DAS AÇÕES AMBIENTAIS PROPOSTAS NO SGA}

\section{1 - Treinamento dos Colaboradores}

Buscando uma melhor implementação do SGA, todos os funcionários são treinados e orientados visando à conscientização e sensibilização dos mesmos. Foi definido um cronograma anual de treinamento conforme o quadro5. Nos treinamentos são tratados diversos assuntos relacionados a produção e ao meio ambiente, com foco nos indicadores de desempenho ambiental. 
Quadro 5: Cronograma de Treinamento

\begin{tabular}{|c|c|c|c|c|c|c|c|c|c|c|c|}
\hline \multicolumn{12}{|c|}{ CRONOGRAMA ANUAL DE TREINAMENTO } \\
\hline Jan & Fev & Mar & Abr & Mai & Jun & Jul & Ago & Set & Out & Nov & Dez \\
\hline & $\mathbf{X}$ & & & & $\mathbf{X}$ & & & & $\mathbf{X}$ & & \\
\hline \multicolumn{12}{|c|}{ Assuntos Tratados } \\
\hline \multicolumn{6}{|c|}{ 1. Economia de água. } & \multicolumn{6}{|c|}{$\begin{array}{l}\text { 5. Apresentação de Gráficos indicadores } \\
\text { ambientais. }\end{array}$} \\
\hline \multicolumn{6}{|c|}{ 2. Economia de Energia. } & \multicolumn{6}{|c|}{$\begin{array}{l}\text { 6. Reciclagem de Lâmpadas, Papel, Plásticos e } \\
\text { outros; }\end{array}$} \\
\hline \multicolumn{6}{|c|}{ 3. Desperdícios Internos } & \multicolumn{6}{|c|}{ 7. Sistema de Gestão Ambiental da empresa; } \\
\hline \multicolumn{6}{|c|}{ 4. Coleta Seletiva. } & \multicolumn{6}{|c|}{$\begin{array}{l}\text { 8. PPHO`s (Procedimento Padrão de Higiene } \\
\text { Operacional) e BPF (Boas Práticas de Fabricação). }\end{array}$} \\
\hline \multicolumn{12}{|c|}{ Responsável pelo Treinamento: Coordenador SGA } \\
\hline
\end{tabular}

Fonte: Autor

\section{2 - Disposição dos resíduos sólidos e líquidos}

Durante a implementação do SGA, algumas ações foram realizadas visando tornar o laticínio ambientalmente correto, onde foram adotadas e implementadas medidas visando à disposição correta dos resíduos sólidos gerados na indústria de laticínios. É importante frisar que foi implantado o sistema de monitoramento, o qual consiste em quantificar todos os resíduos gerados no laticínio, o monitoramento consiste em planilhas eletrônicas que posteriormente ao preenchimento são imprimidas e mantidas em arquivo para apresentação a auditorias e fiscalizações dos órgãos ambientais.

\section{3 - Papel, papelão e plástico}

Foi construído no laticínio um galpão visando à estocagem temporária dos resíduos sólidos e a sua disposição correta. Em vários pontos da indústria foram instalados recipientes coletores, visando à coleta adequada de papel, papelão, plástico e resíduos sólidos não recicláveis. Para isso, todos os funcionários foram treinados e orientados visando à disposição correta dos resíduos nos recipientes. Diariamente estes resíduos são recolhidos e destinados para o galpão de estocagem temporária. Os resíduos não recicláveis são destinados para a caçamba da coleta pública, os quais são removidos para o aterro municipal.

\section{4 - Lâmpadas Fluorescentes}

Todas as lâmpadas fluorescentes que são trocadas no laticínio são recolhidas e destinadas para 
a estocagem temporária em recipientes próprios. Após juntar-se uma certa quantidade, estas lâmpadas são destinadas para empresa de reciclagem de lâmpadas, que reaproveita toda a lâmpada, desde o mercúrio altamente degradante ao meio ambiente até o vidro contido na lâmpada.

\section{5 - Resíduos contaminados com óleo lubrificante}

Os resíduos como estopa, panos e recipientes que estão contaminados com óleo lubrificante são recolhidos e estocados temporariamente em recipientes próprios. Após estocagem são destinados para aterro industrial licenciado pela FEAM para receber estes resíduos.

\section{6 - Óleo Lubrificante Usado}

Todo o óleo lubrificante quando trocado nas máquinas é coletado em recipientes próprios, estocado e posteriormente destinado para empresa de reaproveitamento, onde é aproveitado para rerrefino. Tal procedimento evita que o óleo seja descartado de maneira incorreta, causando grande impacto ambiental.

\section{7 - Carvão e Cinzas das caldeiras}

Os resíduos de carvão e cinzas gerados nas caldeiras alimentadas por madeira (lenha) de eucalipto são recolhidos diariamente e destinados para adubação orgânica de 4 hectares de pastagem utilizada para alimentar os animais da empresa.

\section{8 - Soro de Leite}

Uma das ações mais importante realizada no laticínio consiste na doação de todo o excedente de soro gerado no processo de fabricação dos queijos. O soro é doado para produtores e criadores de porcos, onde o mesmo é utilizado na alimentação dos animais. Este procedimento evita que o maior poluente gerado no laticínio seja destinado para o Sistema de Tratamento Primário e posteriormente para a ETE da COPASA, o que traz grandes benefícios para o meio ambiente.

\section{9 - Reaproveitamento de Água}

Em toda a indústria de laticínios foram instalados sistema de tubulações que consiste no reaproveitamento de água utilizada no processo industrial. Parte desta água reaproveitada é utilizada na limpeza de piso, paredes, pré-enxague de tanques granelizados, etc. A outra parte é utilizada em sistema de irrigação de 4 hectares de pastagem utilizada para alimentar animais da empresa, conforme as figuras 9 e 10. Com a implantação deste processo é possível minimizar o consumo de água e melhorar o coeficiente de consumo de água no laticínio. 


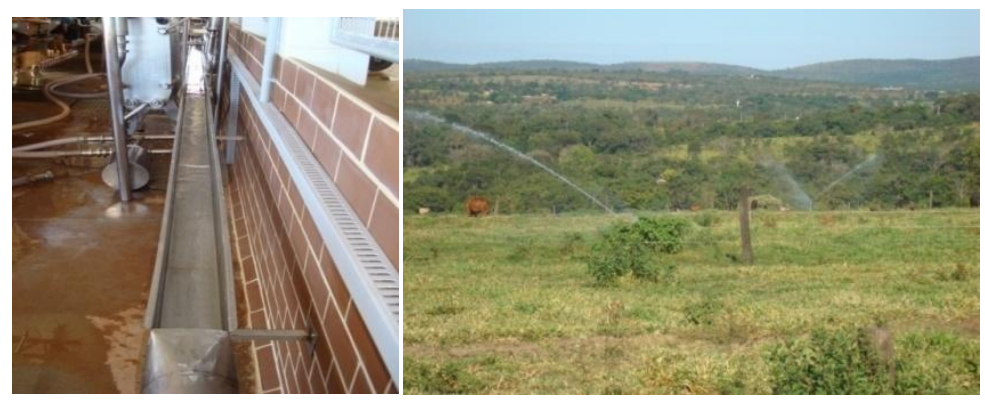

Figuras 10 e 11: Reaproveitamento de água para irrigação de pastagem Fonte: Autor

As figuras 10 e 11 ilustram a gestão da água na indústria, as fotos mostram o sistema de coleta da água residuaria visando o seu reaproveitamento na irrigação de pastagem.

\section{5 - OBJETIVOS E METAS PARA IMPLEMENTAÇÃO DO PROGRAMA DE SGA}

$\mathrm{Na}$ implementação do programa SGA foi adotado conforme quadro 6, os objetivos e metas visando aprimorar e aperfeiçoar seu desempenho ambiental. Para atingir as metas estipuladas no SGA, é fundamental que a empresa priorize o treinamento de seus funcionários e busque melhorias continuas dentro do seu processo, com investimentos em novas tecnologias e novos equipamentos, além de treinamento constante dos funcionários.

Quadro 6: Objetivos e Metas do Programa SGA

\begin{tabular}{|l|l|}
\hline \multicolumn{1}{|c|}{ OBJETIVOS } & \multicolumn{1}{c|}{ METAS } \\
\hline $\begin{array}{l}\text { Aperfeiçoar o consumo de água na indústria de } \\
\text { laticínios }\end{array}$ & $\begin{array}{l}\text { Redução anual de 5\% no coeficiente de consumo de } \\
\text { água }\end{array}$ \\
\hline Aperfeiçoar o consumo de produtos químicos & $\begin{array}{l}\text { Consumir somente produtos biodegradáveis e otimizar } \\
\text { o consumo dos produtos com redução anual de 5\%. }\end{array}$ \\
\hline $\begin{array}{l}\text { Aperfeiçoar a geração de efluente líquido gerado no } \\
\text { processo industrial }\end{array}$ & $\begin{array}{l}\text { Redução anual de 5\% no efluente líquido enviado para } \\
\text { tratamento na ETE COPASA. }\end{array}$ \\
\hline $\begin{array}{l}\text { Aperfeiçoar o consumo de energia elétrica } \\
\text { Melhorar o consumo de energia vegetal (Madeira) }\end{array}$ & $\begin{array}{l}\text { Reduzir o consumo atual de energia com aplicações de } \\
\text { novas tecnologias nos próximos 5 anos. }\end{array}$ \\
\hline $\begin{array}{l}\text { Aperfeiçoar a geração de resíduos sólidos no processo anual em 5\% o consumo de madeira. } \\
\text { industrial, bem como melhorar sua eficiência no } \\
\text { reaproveitamento e reciclagem destes resíduos. }\end{array}$ & $\begin{array}{l}\text { Reduzir em 5\% nos próximos 5 anos a geração de } \\
\text { resíduos sólidos como papel, papelão, plásticos, metal, } \\
\text { carvão, cinza e Lodo (Sólidos Gordurosos). }\end{array}$ \\
\hline $\begin{array}{l}\text { Implantar programa de educação ambiental contínua } \\
\text { no laticínios. }\end{array}$ & $\begin{array}{l}\text { O programa de educação ambiental deverá envolver } \\
\text { todos os funcionários do setor, com implantação nos } \\
\text { próximos cinco anos. }\end{array}$ \\
\hline
\end{tabular}

Fonte: Autor

A empresa já possui implantado em seu processo industrial os programas de qualidade BPF (Boas Praticas de Fabricação), PPHO (Procedimento Operacional Padrão) e APPCC (Analise 
Perigos e Pontos Críticos de Controle). Estes programas permitem o treinamento de todos os funcionários, fazendo com que os mesmos sejam treinados constantemente, padronizando todas as etapas de trabalho desenvolvidas em seus setores.

Com a padronização de execução das tarefas descritas nos procedimentos, os funcionários passam a executar de maneira consciente o seu trabalho, reduzindo gastos e desperdícios, ajudando a melhorar o SGA da empresa, buscando sempre melhorias contínuas e melhorando os indicadores ambientais estipulados pelo SGA.

\section{1 - Avaliação do Programa de Sistema de Gestão Ambiental da Empresa}

Visando buscar sempre as melhorias contínuas na empresa, foi adotado periodicamente uma avaliação completa do programa, a qual é realizada quadrimestralmente pela equipe de SGA implantada na empresa.

A equipe é responsável pela avaliação do cumprimento das metas, observando a necessidade de implementar novas ações corretivas para atingir as metas. Toda a avaliação é realizada de acordo com a lista de avaliação do SGA, verificando os procedimentos, resultados e envolvimento dos funcionários com o programa. Todos indicadores são comparados, verificando antes e depois da implantação do SGA, onde é feita uma quantificação dos resultados obtidos, observando alguns itens como:

- Redução das perdas de matéria prima e produtos acabado.

- Redução da geração de efluente líquido enviado para tratamento.

- Envio de resíduos sólidos para reciclagem.

- Redução dos impactos ambientais.

- Aumento de produtividade e outros fatores importantes relacionados ao programa SGA.

Também são verificados outros fatores e benefícios indiretos que são importantes, entre eles podemos citar: A melhoria do relacionamento com a vizinhança local e com os órgãos ambientais, também é avaliando a consciência ambiental dos funcionários na empresa, Observando o envolvimento dos colaboradores com o SGA.

\section{2 - Manutenção do Programa de SGA}

Buscando sempre a sustentabilidade do programa de SGA da empresa foi adotado pelo programa a realização de treinamentos periódicos para todos os funcionários da empresa, buscando sempre a conscientização e participação dos mesmos no programa.

Através de todos os monitoramentos realizados dentro do programa, conseguimos checar e observar se o programa SGA está sendo bem implementado.

Quando o programa SGA não atingir os resultados definidos em metas, a equipe SGA 
deverá reavaliar o programa, identificando as causas do insucesso, propondo medidas corretivas que serão aplicadas no processo, buscando sempre a melhoria contínua do desempenho ambiental da empresa.

\section{6 - AVALIAÇÃo DOS RESULTADOS E DISCUSSÕES}

\section{1 - Monitoramento do Efluente}

O quadro 7 apresenta os resultados do monitoramento realizado no efluente do laticínios entre o período de Setembro/14 a Setembro/15. Visando uma uniformidade e padronização todas as coletas foram efetuadas antes da entrada do processo de tratamento primário conforme figura $12 \mathrm{e}$ 13. As coletas foram feitas de forma composta com três coletas durante o dia, sendo intercaladas nos horários de 8:00 hs, 12:00 hs e 16:00 hs. Tanto as coletas como as análises foram efetuadas pelo Laboratório Campo, laboratório contratado para realizar o monitoramento.

O intuito de inserir o monitoramento no Programa de SGA teve como objetivo principal identificar a carga poluidora média do laticínio relacionando estes resultados com a implantação do Programa SGA.

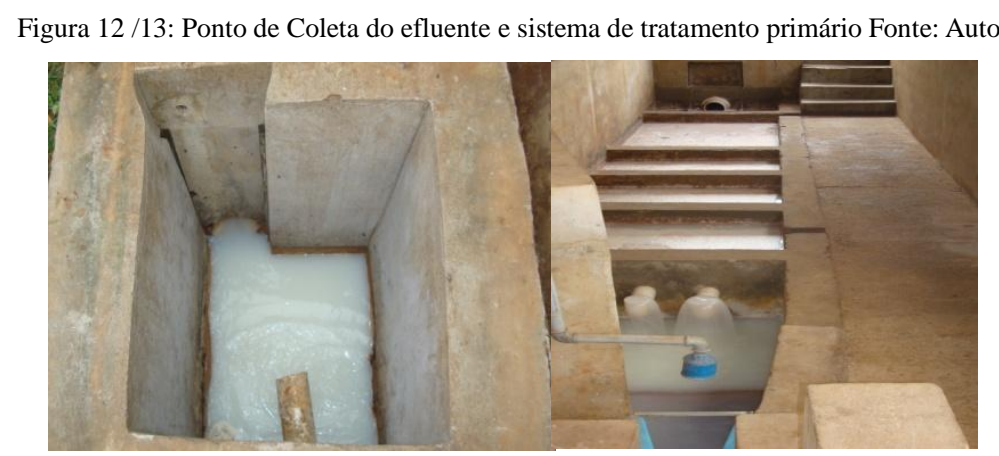

As figuras 12 e 13 ilustram o local de coleta das amostras coletadas durante o monitoramento do efluente líquido.

\begin{tabular}{|c|c|c|c|c|c|c|c|c|c|c|c|c|c|c|}
\hline & & & & & SULTAD & S OBTI & $\begin{array}{l}\text { ADRO } 7 \\
\text { OS NO N }\end{array}$ & DNITOR & MENTO & & & & & \\
\hline $\begin{array}{l}\text { PARÂMETR } \\
\text { OS }\end{array}$ & $\begin{array}{c}\text { Jan/13 } \\
\text { a } \\
\text { Ago/14 }\end{array}$ & Set/14 & Out/14 & Dez/14 & Jan/15 & Fev/15 & Mar/15 & Abr/15 & Mai/15 & Jun/15 & $\mathrm{Jul} / \mathbf{1 5}$ & Ago/15 & Set/15 & MÉDIA \\
\hline $\begin{array}{l}\text { DQO mg } \\
\text { O2/L }\end{array}$ & $3.498,8$ & $\begin{array}{c}2.320 \\
0\end{array}$ & $1.720,0$ & $6.560,0$ & $1.333,0$ & $4.640,0$ & $4.520,0$ & $3.270,0$ & $4.980,0$ & $2.360,0$ & $2.240,0$ & $1.290,0$ & 1.700 , & $3.077,7$ \\
\hline
\end{tabular}




\begin{tabular}{|c|c|c|c|c|c|c|c|c|c|c|c|c|c|c|}
\hline O.G mg/L & 892,1 & $\begin{array}{c}492,3 \\
2\end{array}$ & 717,0 & $9.087,0$ & $1.795,0$ & $14.515,0$ & $9.648,3$ & $9.107,2$ & $4.974,0$ & $2.115,6$ & $1.574,8$ & 790,82 & 298,0 & $4.592,9$ \\
\hline $\begin{array}{l}\text { Surfactantes } \\
\text { Aniônicos } \\
\text { mg/L }\end{array}$ & 20,1 & 20,80 & 36,6 & 16,0 & 73,6 & 34,0 & 38,0 & 6,0 & 7,20 & 30,40 & 24,60 & 18,4 & 51,60 & 29,7 \\
\hline $\mathbf{P h}$ & 9,3 & 11,28 & 9,36 & 10,06 & 10,29 & 10,80 & 10,89 & 9,10 & 9,24 & 8,65 & 8,58 & 7,84 & 10,13 & 9,68 \\
\hline $\begin{array}{l}\text { Carga } \\
\text { Orgânica } \\
\text { Kg/dia* 1.000 }\end{array}$ & 340,0 & 46,27 & $*$ & 485,05 & 173,31 & 216,43 & $*$ & 334,59 & 243,24 & 192,87 & 213,70 & 150,34 & $\begin{array}{c}192,6 \\
4\end{array}$ & 187,37 \\
\hline
\end{tabular}

\section{2 - DBO (Demanda Bioquímica de Oxigênio)}

O parâmetro de DBO indica indiretamente a quantidade de matéria orgânica biodegradável no efluente, quanto mais alto os valores, maior será a carga orgânica contida no mesmo. Os valores deste parâmetro para as águas naturais são inferiores a 5 mg/L (LIBÂNIO, 2008).

Conforme o quadro 7, os resultados apresentados no monitoramento do efluente, mostra que de Janeiro/13 a Ago/14 obteve-se uma média de 1.200,0 mgO2/L. Neste período que antecedeu a implantação e implementação do SGA a recepção média de leite no laticínios foi de 150.000 litros de leite ao dia. Durante a implantação e implementação do programa SGA, ou seja, no período de Setembro/14 a Setembro/15, obtiveram-se uma média de 1.578,9mg O2/L, com média de 185.000 litros de leite por dia. Portanto a média apresentou resultado superior ao que antecedeu a implantação do SGA, porém uma das justificativas foi que a indústria apresentou uma recepção média de leite de 185.000 litros de leite, ou seja, recebeu mais leite que no período antecessor. Outro fator que pode ter contribuído para o aumento da DBO foi a grande rotatividade de funcionários neste período, fator que influência diretamente nestes resultados devido a falta de treinamento dos funcionários novatos.

\section{3 - DQO (Demanda Química de Oxigênio)}

De acordo com estudos realizados, os valores apresentados por este parâmetro são geralmente mais altos que os valores da DBO, o qual é de grande importância por relacionar com a quantidade de oxigênio necessário para oxidar a matéria orgânica através de agentes químicos (CETESB, 2010).

Os resultados deste parâmetro comparando-se a média no período que antecedeu sendo de Jan/13 a Ago/14 foi de 3.498,8 $\mathrm{mg}$ O2/L. A média obtida no período de implantação e implementação do SGA, sendo de Set/14 a Set/15 foi de 3.077,7 mg O2/L, portanto obteve-se uma pequena melhora neste parâmetro, apesar de ter as mesmas condições para o parâmetro de DBO, este parâmetro está relacionado com a oxidação da matéria orgânica via agentes químicos, o que 
pode explicar as diferenças entre estes resultados.

\section{4 - SST (sólidos suspensos totais)}

Os sólidos totais referem-se as pequenas partículas sólidas que se mantém em suspensão na água, sendo um dos parâmetros utilizados como um indicador de qualidade do efluente, onde quanto menor o tamanho das partículas, maior será a carga poluente susceptível de ficar em suspensão (CETESB, 2010).

Os resultados apresentados no monitoramento mostra que de jan/13 a agos/14 o efluente obteve uma média de $831,1 \mathrm{mg} / \mathrm{L}$ e durante o período de Set/14 a Set/15, a média obtida foi de $2.674,1 \mathrm{mg} / \mathrm{L}$, portanto resultados bem acima da média anterior. O quadro 8 mostra que no período entre os meses de abril/13 a junho/14 os resultados tiveram uma grande alteração com forte aumento de SST em relação aos outros meses do monitoramento, influenciando no aumento da média. Este aumento pode ter variado em função do aumento do número de limpezas de equipamentos devido ao aumento da produção de derivados do leite.

\section{5 - O.G (óleos e graxas)}

Este parâmetro refere-se à quantidade de óleos e graxas de origem animal presentes no efluente líquido, onde pode-se relacionar este resultado a perda de resíduos gordurosos no efluente.

Os resultados no período entre jan/13 a Ago/14 apresentaram uma média de 892,1 mg/L e no período de implantação do SGA os resultados obtidos foram de 4.592,0 mg/L, portanto bem acima da média anterior. Mais uma vez relacionou este aumento na média deste parâmetro com o aumento na produção dos derivados do leite neste período, o que acarretou mais limpezas em equipamentos e estruturas físicas, com maior lançamento deste resíduo no efluente, tendo como conseqüência o aumento deste parâmetro no efluente líquido do laticínio.

\section{6 - Surfactantes aniônicos}

Os surfactantes ou detergentes são substâncias utilizadas em grande escala em um laticínio, principalmente na limpeza de estruturas físicas como paredes e pisos e na limpeza manual dos equipamentos e utensílios utilizados no laticínio.

Os resultados do monitoramento mostram que no período de Jan/13 a Agos/14 obteve-se uma média de 20,1 mg/L e no período de Set/14 a Set/15, o resultado foi de 29,7 mg/L, portanto um pequeno aumento. Mais uma vez teve-se que levar em consideração o crescimento da produção do laticínio, o que proporcionou aumento na quantidade de superfícies a serem limpas, como paredes, pisos e equipamentos. O mais importante é que os resultados apresentaram-se bem próximos, mostrando que o consumo de detergentes foi proporcional ao aumento da quantidade de 
equipamentos, ou seja, o consumo consciente, evitando desperdícios durante o processo.

\section{7 - pH - Potencial Hidrogeniônico}

O pontencial hidrogeniônico $(\mathrm{pH})$, representa a intensidade da condição ácida ou alcalina de um meio, medindo a acidez ou alcalinidade de uma solução, onde o seu valor para água natural e pura a $25^{\circ} \mathrm{c}$ é igual a 7,0 .

A média de pH obtida no período de Jan/13 a Agos/14 foi de 9,30, durante o período de implementação do SGA, a média de pH obtida no efluente foi de 9,68. A Legislação Federal, CONAMA 357, permite pH entre 6,0 a 9,0 para disposição final em qualquer corpo hidríco. Estes resultados nos mostra que o efluente líquido tem a tendência forte de alcalinidade, o que está relacionado com a grande quantidade de produtos alcalinos utilizados na limpeza dos equipamentos do laticínios. Toda a solução de enxague dos balões e tubulações são descartadas no efluente, visando o tratamento final na ETE da COPASA.

\section{8 - Carga orgânica}

A carga orgânica retrata a quantidade de matéria orgânica contida no efluente durante a coleta de acordo com a vazão total do mesmo medida no medidor de vazão do efluente. $\mathrm{O}$ monitoramento nos mostra que a média da carga orgânica obtida no período de jan/13 a agos/14 foi de 340.000 $\mathrm{kg}$ /dia e no período de implementação do SGA foi de $187.000 \mathrm{~kg} /$ dia,portanto teve-se uma grande redução nacarga orgânica do efluente no período de implementação do SGA. É importante frisar que que a quantidade de matéria orgânica está relacionada diretamente com a vazão do efluente no dia da coleta, ou seja, quanto maior a produção de derivados, maior será a quantidade de efluente gerado e maior será a carga orgânica do efluente.

\section{9 - Relação do coeficiente litros de água para cada litro de leite recebido}

A relação de consumo de água baseado no recebimento de leite é de grande importância visando o controle e acompanhamento do gasto de água. Em um laticínios quanto maior for o recebimento de leite, maior será a utilização de água com limpeza dos tanques granelizados de transporte do leite, tubulações e equipamentos. No quadro 9 pode-se verificar a utilização de água pela indústria de laticínios desde o mês de Janeiro/14, bem como o total de leite recebido neste período. A água do laticínios é obtida de dois poços artesianos, ambos estão em processo de renovação de outorga, sendo que os dois poços funcionam em período alternado durante o dia visando atender as condicionantes do IGAM. Os dois poços possuem hidrômetros e horímetros visando o controle de água gasto por dia e o controle do total de horas de funcionamento por dia, atendendo as condicionantes da outorga. A água é o principal recurso natural utilizado pelo laticínio, 
por isso a importância de monitorar o consumo e introduzir melhorias no processo visando obter economias no processo.

Quadro 9: Planilha de Controle de Leite Recebido / Água Utilizada

\begin{tabular}{|c|c|c|c|}
\hline Mês & Consumo de Água & Lts de Leite Recebido & $\begin{array}{c}\text { Coeficiente Lts água/ } \\
\text { Lts Leite }\end{array}$ \\
\hline jan/14 & 6.488 .000 & 5.775 .771 & 1,12 \\
\hline fev/14 & 6.228 .000 & 5.069 .025 & 1,23 \\
\hline mar/14 & 7.300 .000 & 5.856 .532 & 1,25 \\
\hline abr/14 & 6.837 .000 & 5.687 .253 & 1,20 \\
\hline mai/14 & 7.506 .000 & 5.832 .031 & 1,29 \\
\hline jun/14 & 6.967 .000 & 5.793 .798 & 1,20 \\
\hline jul/14 & 7.134 .000 & 6.117 .068 & 1,17 \\
\hline ago/14 & 6.671 .000 & 6.178 .322 & 1,08 \\
\hline Total & 55.131 .000 & 46.309 .800 & 1,19 \\
\hline Média & 6.891 .375 & 5.788 .725 & 1,19 \\
\hline set/14 & 6.536 .000 & 5.893 .854 & 1,11 \\
\hline out/14 & 7.062 .000 & 6.200 .639 & 1,14 \\
\hline nov/14 & 7.202 .000 & 6.465 .813 & 1,11 \\
\hline $\mathrm{dez} / 14$ & 7.415 .000 & 6.799 .301 & 1,09 \\
\hline $\mathrm{jan} / 15$ & 7.212 .000 & 6.489 .449 & 1,11 \\
\hline fev/15 & 7.206 .000 & 5.621 .490 & 1,28 \\
\hline $\operatorname{mar} / 15$ & 8.227 .000 & 6.258 .358 & 1,31 \\
\hline abr/15 & 8.125 .000 & 6.042 .016 & 1,34 \\
\hline mai/15 & 8.039 .000 & 6.047 .208 & 1,33 \\
\hline jun/15 & 7.292 .000 & 5.681 .662 & 1,28 \\
\hline $\mathrm{jul} / 15$ & 7.748 .000 & 5.928 .139 & 1,31 \\
\hline ago/15 & 7.267 .000 & 5.931 .849 & 1,23 \\
\hline set/15 & 6.869 .000 & 5.662 .579 & 1,21 \\
\hline Total & 96.200 .000 & 79.022.357 & 1,22 \\
\hline Média & 7.400 .000 & 6.078.643 & 1,22 \\
\hline
\end{tabular}

Fonte: Indústria de Laticínios

O quadro 9 apresenta o consumo de água, o total de leite recebido e o coeficiente de consumo de água no período de Jan/14 a Set/15. Os dados mostram que houve um crescimento no consumo de água no período de implementação do SGA, onde a média de jan/14 a ago/14 foi de 6.891 .375 lts de água e no período de set/14 a set/15 foi de 7.400.000 lts de água, crescimento de 7,38\%. Porém a recepção de leite aumentou de 5.788 .725 lts média/mês para 6.078 .643 lts média/mês no período de implementação do SGA, crescimento de 5,0\%. Estes dados justificam o pequeno aumento do 
coeficiente de consumo de água em relação ao volume de leite recebido, onde ocorreu um aumento de 0,03 . Mesmo com o crescimento da recepção de leite, praticamente o consumo de água foi proporcional quando observa-se que o coeficiente aumentou de 1,19 para 1,22 litros de água para cada litro de leite recebido na indústria de laticínios.

\section{7 - CONCLUSÕES}

A indústria de laticínios obteve melhorias significativas com a implantação do SGA em seu processo produtivo, com gerenciamento total de seus resíduos sólidos, bem como a adoção de procedimentos de controle visando a busca permanente da melhoria continua. Através do monitoramento de seu efluente líquido pode conhecer a quantificar dados reais de seu processo que vão ajudar na implantação de novas tecnologias que possam oferecer alternativas capazes de melhorar o seu desempenho produtivo e ambiental.

Pode-se destacar que a principal contribuição deste trabalho foi oferecer asindústrias de laticínios um modelo de SGA capaz de apresentar alternativas que possam ajudar a melhorar o empenho ambiental da empresa, com várias alternativas de ações que oferecem disposição correta dos resíduos sólidos, alternativas de reaproveitamento de água e outros procedimentos capazes de melhorar as ações ambientais do laticínio, com redução nos custos da empresa.

\section{8 - REFERÊNCIAS}

BOTELHO, H. Reuso de Água. Belo Horizonte, 2004.

BRAGA, B. et al. Introdução à Engenharia Ambiental.2 ed. São Paulo: Pearson Prentice Hall, 2005.

BRANCO, S. M. Meio ambiente \& Biologia. São Paulo: Editora SENAC, 2001.

CAlABRIA, A. F.; SILVA, S. C. G.; FILHO, S. G. C. J.; MEDEIROS, D. D. Aplicação da Produção Mais Limpa em uma empresa como ferramenta de melhoria contínua. Recife, Universidade Federal de Pernanbuco, 2007.

CAMPOS, S. M. L. Indicadores de desempenho dos sistemas de gestão ambiental (SGA): Uma pesquisa teórica. Univali, Santa Catarina, 2008.

DONAIRE, D. Gestão ambiental na empresa. 2.ed. São Paulo: Atlas, 1999.

EMBRAPA. Programa Embrapa de Carne e Qualidade. Embrapa Gado de Corte, Campo Grande, 2000, Revista Leite\&Derivados, São Paulo, ano xv, p. 26-36, mai. 2007.

LIBANIO, M. Fundamentos de Qualidade e Tratamento de Água.2 ed. Campinas: Editora Átomo, 2008. 